\title{
Molecular and Photosynthetic Performance in the Yellow Leaf Mutant of Torreya grandis According to Transcriptome Sequencing, Chlorophyll $a$ Fluorescence, and Modulated $820 \mathrm{~nm}$ Reflection
}

\author{
Jianshuang Shen ${ }^{1}$, Xueqin $\mathrm{Li}^{1}{ }^{1}$, Xiangtao Zhu ${ }^{1}$, Zhicheng Ding ${ }^{1}$, Xiaoling Huang ${ }^{1}$, Xia Chen ${ }^{1}$ \\ and Songheng Jin ${ }^{1,2}$,*
}

Citation: Shen, J.; Li, X.; Zhu, X.; Ding, Z.; Huang, X.; Chen, X.; Jin, S.

Molecular and Photosynthetic

Performance in the Yellow Leaf Mutant of Torreya grandis According to Transcriptome Sequencing, Chlorophyll $a$ Fluorescence, and Modulated $820 \mathrm{~nm}$ Reflection. Cells 2022, 11, 431. https://doi.org/ $10.3390 /$ cells 11030431

Academic Editors: Hazem M. Kalaji and Alexander E. Kalyuzhny

Received: 10 December 2021

Accepted: 23 January 2022

Published: 27 January 2022

Publisher's Note: MDPI stays neutral with regard to jurisdictional claims in published maps and institutional affiliations.

Copyright: (C) 2022 by the authors. Licensee MDPI, Basel, Switzerland. This article is an open access article distributed under the terms and conditions of the Creative Commons Attribution (CC BY) license (https:// creativecommons.org/licenses/by/ $4.0 /)$.
1 Jiyang College, Zhejiang A\&F University, Zhuji 311800, China; shenjianshuang18@163.com (J.S.); lxqin@zafu.edu.cn (X.L.); zxt8202@163.com (X.Z.); zuzims@163.com (Z.D.); JYXYhxl@aliyun.com (X.H.); comchenxia1212@yeah.net (X.C.)

2 State Key Laboratory of Subtropical Silviculture, School of Forestry and Biotechnology, Zhejiang A\&F University, Lin'an, Hangzhou 311300, China

* Correspondence: shjin@zafu.edu.cn

Abstract: To study the photosynthetic energy mechanism and electron transfer in yellow leaves, transcriptomics combined with physiological approaches was used to explore the mechanism of the yellow leaf mutant Torreya grandis 'Merrillii'. The results showed that chlorophyll content, the maximal photochemical efficiency of PSII $\left(F_{v} / F_{m}\right)$, and the parameters related to the OJ phase of fluorescence $\left(\varphi_{\mathrm{Eo}}, \varphi_{\mathrm{Ro}}\right)$ were all decreased significantly in mutant-type $T$. grandis leaves. The efficiency needed for an electron to be transferred from the reduced carriers between the two photosystems to the end acceptors of the PSI $\left(\delta_{R_{0}}\right)$ and the quantum yield of the energy dissipation $\left(\varphi_{\text {Do }}\right)$ were higher in the leaves of mutant-type T. grandis compared to those in wild-type leaves. Analysis of the prompt fluorescence kinetics and modulated $820 \mathrm{~nm}$ reflection showed that the electron transfer of PSII was decreased, and PSI activity was increased in yellow T. grandis leaves. Transcriptome data showed that the unigenes involved in chlorophyll synthesis and the photosynthetic electron transport complex were downregulated in the leaves of mutant-type T. grandis compared to wild-type leaves, while there were no observable changes in carotenoid content and biosynthesis. These findings suggest that the downregulation of genes involved in chlorophyll synthesis leads to decreased chlorophyll content, resulting in both PSI activity and carotenoids having higher tolerance when acting as photo-protective mechanisms for coping with chlorophyll deficit and decrease in linear electron transport in PSII.

Keywords: comparative transcriptome; photosynthetic electron transport; yellow leaf color mutant; gene expression; photosynthesis

\section{Introduction}

Torreya grandis 'Merrillii', a variety of Torreya grandis Fortune ex. Lindt. (family Taxaceae), is a relict plant from the tertiary period and an important economic species that is widely grown in South China [1-4]. The seeds of T. grandis 'Merrillii' are processed to produce nuts that are served as a snack food with some health benefits [2-4]. A mutant of T. grandis 'Merrillii' with yellow leaves was recently discovered in a wild forest in Zhejiang province by our research team. The yellow leaf trait is stable through grafting and breeding. Plants with yellow leaves, particularly those that can be maintained year after year, play an important role in landscaping applications. The etiolation phenomenon commonly occurs in nature, and has been systematically studied in model plants and crops such as Arabidopsis thaliana [5], Nicotiana tabacum [6], and rice [7]. The molecular mechanisms of the yellow leaf color mutation have been summarized into several types, including gene mutations in the biosynthetic or degradation chlorophyll pathways, gene mutations that occur during 
chloroplast development and in functional pathways, and gene mutations that occur in the light signal transduction pathway [8-10]. Genes that are related to chloroplast development and function in mutants produce abnormal chlorophyll, resulting in the yellow leaf color phenotype. These yellow leaf color mutants are ideal material for an in-depth exploration of the development and function of chloroplasts, and provide excellent germplasm resources for genetic and breeding research [11]. Until now, the formation mechanism, photosynthetic energy, and electron transfer in the yellow leaves of woody plants have not been clearly elucidated.

Previous studies have reported that the composition, content, and distribution of pigments in mesophyll cells, chloroplast structure, and photosynthesis are directly related to leaf color in plants [12]. Biosynthesis of chlorophyll and photosynthesis occur in the chloroplasts of higher plants. Chlorophyll, combined with a specific protein, forms a photosynthetic complex that captures light and transfers electrons. Photosynthetic electron transfer occurs in the thylakoid membranes of chloroplast, and is related to photosystem I (PSI), photosystem II (PSII), and photosynthetic electron carriers [10,13-15]. Measurement of delayed chlorophyll $a$ fluorescence (DF), prompt chlorophyll $a$ fluorescence (PF), and modulated reflection at $820 \mathrm{~nm}$ (MR) is an important way to investigate changes in the photosynthetic electron transfer chain, including the PSI electron acceptor side, electron transport between PSII and PSI, and the PSII electron donor side [16-19]. To our knowledge, this method has not been used to study photosynthetic energy and electron transfer in yellow leaf mutant plants. Photosynthesis occurring in chloroplasts is an important issue in the field of biological research because it completes the conversion process of matter and energy and is the basis for living things. Therefore, research on the photosynthesis mechanism and its regulatory mechanism is needed.

High-throughput transcriptome sequencing (Illumina/Solexa) is widely used to analyze biological processes at the transcription level. High-throughput transcriptome sequencing technology lays the foundation for isolating and identifying the key genes of species without reference genomes, and can be used in molecular marker studies [20]. This technology has been used in several studies related to the molecular formation of yellow leaves in woody plants, including Camellia sinensis 'Baijiguan' [21] and Lagerstroemia indica [22].

The chlorophyll content and chlorophyll/carotenoid ratio, photosynthesis parameters, chlorophyll fluorescence, and expression of related genes were found to be different in green and yellow leaves, while the mechanism for formation of yellow leaves in different species is different [21-24]. Meanwhile, photosynthetic energy and electron transfer, and related gene expression in yellow leaf mutants of T. grandis 'Merrillii' have not been studied. Therefore, we hypothesized that inhibiting chlorophyll synthesis could lead to decreased chlorophyll content and influence electron transfer in photosynthetic reaction centers (RCs), and that photo-protective mechanisms could help cope with chlorophyll deficit in the yellow leaves of T. grandis 'Merrillii'. This study was to research the pigments, chlorophyll $a$ fluorescence, photosynthetic electron transfer, and photosynthetic and chlorophyll synthesis metabolic pathways in the yellow leaves of T. grandis 'Merrillii', and explore the molecular and photosynthetic performance in order to provide a theoretical basis for the breeding, further research, and utilization of yellow leaves. Therefore, in this study, yellow leaf mutants of T. grandis 'Merrillii' were used as material to explore the physiological and molecular mechanisms of photosynthetic energy and electron transfer in its leaves by using physiological and transcriptome sequencing methods.

\section{Materials and Methods}

\subsection{Plant Material}

A total of 18 Torreya grandis 'Merrillii' grafting trees with green $(n=9)$ and yellow $(n=$ 9) leaves were used in our study. In March 2017, these trees were established by using a 1-year-old T. grandis "Merrillii" scion on a 1-year-old T. grandis Fort. Ex Lindl. rootstock. Stem samples (scion) with green leaves and its natural mutant with yellow leaves (Figure 1) 
were collected from one normal plant and one mutant plant of T. grandis 'Merrillii'. The rootstocks were cut about $5 \mathrm{~cm}$ above the root collar, and then grafted with scions. These trees were planted in individual pots $(20 \mathrm{~cm}$ tall, $25 \mathrm{~cm}$ top diameter). Each pot was filled with $7 \mathrm{~kg}$ loam soil (field water holding capacity of $33 \%$ ), watered when the pot was naturally dried (watered to saturation each time, about $0.5 \mathrm{~L}$ per pot), and fertilized per month with a half-strength Hoagland solution. Plants were placed outdoors at the Zhejiang A\&F University $\left(30^{\circ} 14^{\prime} \mathrm{N}, 119^{\circ} 44^{\prime} \mathrm{E}\right)$ in Lin'an, Zhejiang, China, and grown for three years under these conditions (annual average temperature is $15^{\circ} \mathrm{C} \sim 23^{\circ} \mathrm{C}$, annual solar emissivity is $\left.(419 \sim 502) \times 10^{4} \mathrm{KJ} / \mathrm{m}^{2}\right)$. On a sunny day on March 16, 2020, three replicates (three pots per replicate) of T. grandis 'Merrillii' with green leaves (WT) and three replicates of its natural mutant with yellow leaves (MT) were randomly selected and used as test materials in this study.

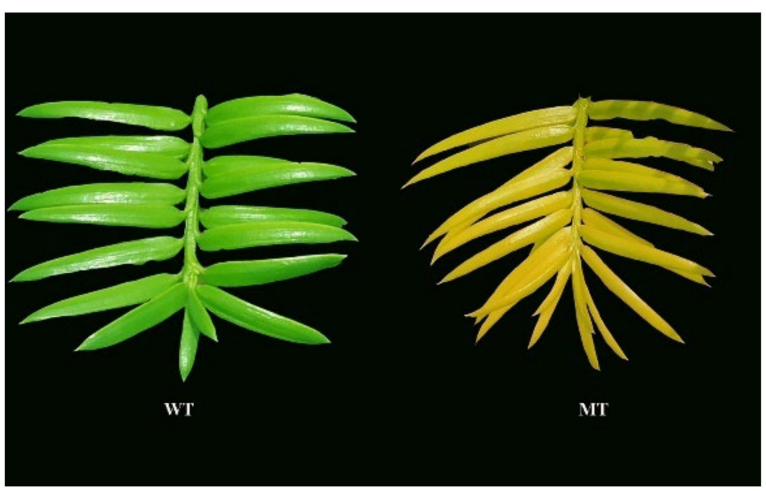

Figure 1. Branches of mutant-type and wild-type Torreya grandis 'Merrillii'. (WT means wild type; MT means mutant-type yellow leaf).

\subsection{Measurement of Leaf Pigment Content}

The mature third and fourth leaves from the top of the shoots were collected, weighed $\left(0.1 \mathrm{~g}\right.$ per sample), frozen in liquid nitrogen, and stored at $-80^{\circ} \mathrm{C}$. The concentrations of chlorophyll $a(\mathrm{Chl} a)$, chlorophyll $b(\mathrm{Chl} b)$, and total carotenoids were determined using Lichtenthaler's method $[25,26]$. WT and MT grafted T. grandis 'Merrillii' were randomly selected with three replicates, with three pots per replicate.

\subsection{Simultaneous Measurement of PF, DF, and MR Kinetics}

The measurements were made on the mature third and fourth leaves from the top of the shoots. The PF, DF, and MR kinetics were measured simultaneously after 30 min dark adaptation using a Multi-Function Plant Efficiency Analyzer (PE304NE, M-PEA, Hansatech, Norfolk, UK). A saturating light pulse $\left(5000 \mu \mathrm{mol}\right.$ photons $\left.\mathrm{m}^{-2} \mathrm{~s}^{-1}\right)$ was emitted by the M-PEA. MR light reflection was measured separately with far-red light of $1000 \mu \mathrm{mol}$ photons $\mathrm{m}^{-2} \mathrm{~s}^{-1}$. The emitter wavelengths were $635 \pm 10 \mathrm{~nm}$ for the actinic light LED, $820 \pm 25 \mathrm{~nm}$ for the modulated light LED, and $735 \pm 15 \mathrm{~nm}$ for the far-red light LED. High-quality optical bandpass filters were used to protect the PF, DF (730 $\pm 15 \mathrm{~nm}$ ), and MR $(820 \pm 20 \mathrm{~nm})$ detectors. The PF, $\mathrm{MR}_{820 \mathrm{~nm}}$, and DF were simultaneously measured when PF, DF, and MR light reflection and the light-dark conversion started $300 \mu$ s after exposure. The PF and MR light reflection signals were recorded in the light, and the DF signals were recorded in the dark [16]. The PF, DF, and MR kinetics curves were prepared in accordance with the methods described in previous studies $[16,19,27]$. Prompt chlorophyll fluorescent transients (OJIP transients) were quantified in accordance with the original data; minimal fluorescence intensity $\left(\mathrm{F}_{\mathrm{O}}\right.$, when all PSII RCs are open; recorded $20 \mu$ s after start of actinic illumination); maximum fluorescence intensity $\left(\mathrm{F}_{\mathrm{m}}\right.$, when all PSII reaction centers are closed); and fluorescence intensities at $300 \mu \mathrm{s}\left(\mathrm{F}_{\mathrm{K}}\right), 2 \mathrm{~ms}\left(\mathrm{~F}_{\mathrm{J}}\right)$, and $30 \mathrm{~ms}\left(\mathrm{~F}_{\mathrm{I}}\right)$. Some parameters were calculated from the measured OJIP transients $[16,18,19]$, including the relative variable fluorescence at the J-step $\left(\mathrm{V}_{\mathrm{J}}\right)$, a trapped exciton moves an electron 
into the electron transport chain beyond $\mathrm{Q}_{\mathrm{A}}{ }^{-}\left(\psi_{\mathrm{o}}\right)$, the efficiency required for an electron to be transferred from reduced carriers between the two photosystems to the PSI end acceptors $\left(\delta_{\mathrm{Ro}}\right)$, a given chlorophyll $a$ molecule that functions as the PSII RC $\left(\gamma_{\mathrm{RC}}\right)$, the quantum efficiency of electron transport at $\mathrm{t}=\mathrm{F}_{\mathrm{O}}\left(\varphi_{\mathrm{Eo}}\right)$, the quantum yield for reduction of the terminal electron acceptors on the PSI acceptor side $\left(\varphi_{\mathrm{Ro}}\right)$ ), the quantum efficiency of energy dissipation at $t=F_{o}\left(\varphi_{\text {Do }}\right)$, the $Q_{A}{ }^{-}$reducing active $R C$ s per cross section (CS) at $t=F_{\mathrm{O}}\left(\mathrm{RC} / \mathrm{CS}_{\mathrm{o}}\right)$ and at $\mathrm{t}=\mathrm{F}_{\mathrm{m}}\left(\mathrm{RC} / \mathrm{CS}_{\mathrm{M}}\right)$, the absorption flux (ABS) of the antenna chlorophylls per $\mathrm{RC}(\mathrm{ABS} / \mathrm{RC})$, the trapped energy flux per $\mathrm{RC}\left(\mathrm{TR}_{0} / \mathrm{RC}\right)$, the dissipated energy flux per $\mathrm{RC}\left(\mathrm{DI}_{0} / \mathrm{RC}\right)$, the electron transport flux per $\mathrm{RC}\left(\mathrm{ET}_{0} / \mathrm{RC}\right)$, the electron flux-reducing end electron acceptors at the PSI acceptor side per $\mathrm{RC}\left(\mathrm{RE}_{0} / \mathrm{RC}\right)$, the $\mathrm{ABS}$ per CS at $t=F_{m}\left(A B S / C S_{M}\right)$, the trapped energy flux per CS at $t=F_{m}\left(R_{0} / C S_{M}\right)$, the dissipated energy flux per $\mathrm{CS}$ at $\mathrm{t}=\mathrm{F}_{\mathrm{m}}\left(\mathrm{DI}_{0} / \mathrm{CS}_{\mathrm{M}}\right)$, the electron flux per per $\mathrm{CS}\left(\mathrm{at} t=\mathrm{F}_{\mathrm{m}}\right)$ $\left(\mathrm{ET}_{0} / \mathrm{CS}_{\mathrm{M}}\right)$ and the electron transport flux per CS at $\mathrm{t}=\mathrm{F}_{\mathrm{m}}\left(\mathrm{RE}_{0} / \mathrm{CS}_{\mathrm{M}}\right)$. DF is an obvious 20 s dark time point (the first reliable DF measurement value during each dark time interval), and it was selected during different time domains (from microseconds to minutes) to draw the DF-induced kinetic curve. The characteristic $\mathrm{I}_{1}$ was the first maximum of the DF curve (at $7 \mathrm{~ms}$ ), $\mathrm{I}_{2}$ was the second maximum (at $100 \mathrm{~ms}$ ), and $\mathrm{D}_{2}$ was the minimum of the curve. The MR kinetic was expressed as MR/MR $\mathrm{M}_{\mathrm{O}}$, where $\mathrm{MR}$ is the modulated reflected signal during illumination and $\mathrm{MR}_{\mathrm{O}}$ is the first reliable MR measurement (taken at $0.7 \mathrm{~ms}$ ). Three leaf replicates from wild-type and mutant-type $T$. grandis 'Merrillii' were randomly selected (three pots per replicate).

\subsection{Transcriptome Sequencing}

Three biological replicates of leaves from wild-type and mutant-type of T. grandis 'Merrillii' were randomly selected (three pot per replicate). Mature third and fourth leaves from the top of the shoots were collected, frozen in liquid nitrogen, and stored at $-80^{\circ} \mathrm{C}$. Thus, there were six samples, with each sample containing the leaves (6-8 leaves randomly selected) from the three pots.

Total RNA extraction, RNA integrity evaluation and DNA libraries construction were made according to Han et al. [28]. The DNA libraries were sequenced using the Illumina HiSeq 2000 sequencing platform. RNA-seq, quality control, transcriptome assembly, gene functional annotation, gene expression analysis, and gene ontology (GO) and KEGG orthologue enrichment analyses were aided by the Novogene Biological Information Technology Co., Ltd. (Beijing, China) [28]. The thresholds for determining differentially expressed genes (DEGs) were set at $\mid \log 2$ (Foldchange) $\mid \geq 1$ and $p$ value $<0.05$. The differences in gene expression level were considered significant when a gene was identified as being differentially expressed. Multiple Benjamini-Hochberg tests had a false discovery rate (FDR) of $5 \%(p<0.05)[29]$.

\subsection{Quantitative Real-Time Polymerase Chain Reaction ( $q$ RT-PCR) Validation}

Total cellular RNA was purified using Trizol RNA reagent (Life Technologies, Carlsbad, CA, USA) following the manufacturer's instructions, and stored at $-80{ }^{\circ} \mathrm{C}$. qRT-PCR analysis was performed using the PrimeScript ${ }^{\mathrm{TM}} \mathrm{RT}$ reagent kit with gDNA Eraser (perfect real time; Code No. RR047; Takara, Shiga, Japan) following the manufacturer's instructions. Both the qRT-PCR methods and cycling conditions of PCR reactions were used by Shen et al. [30]. Three technical replicates for each of the three biological repeats were performed for each sample using cyclophilin (CYP, Cluster-41647.20988) as the internal control. The gene-specific primers were designed using Primer 5.0, and are listed in Table S1.

\subsection{Statistical Analysis}

One-way analysis of variance was carried out using Excel 2019 (Microsoft Inc., Redmond, WA, USA) and SPSS software (version 22.0; SPSS Inc., Chicago, IL, USA) for physiological data sets and to chart relevant parameters. Means were compared using the least significant difference test. $p$-values $<0.05$ were considered significant. 


\section{Results}

\subsection{Analysis of Pigment Contents}

As shown in Table 1, the $\mathrm{Chl} a$ and $\mathrm{Chl} b$ contents and the $\mathrm{Chl} a / b$ ratio in $T$. grandis 'Merrillii' leaves decreased significantly in the mutant-type plants. However, no differences in carotenoid content were observed between the mutant-type and wild-type plants.

Table 1. Photosynthetic pigment contents in leaves of mutant-type and wild-type Torreya grandis 'Merrillii'.

\begin{tabular}{cccccc}
\hline $\begin{array}{c}\text { Torreya } \\
\text { grandis } \\
\text { 'Merrillii' }^{\text {Mra }}\end{array}$ & Chl $\boldsymbol{a}(\mathbf{m g} / \mathbf{g})$ & Chl $\boldsymbol{b}(\mathbf{m g} / \mathbf{g})$ & $\begin{array}{c}\text { Chl }(\boldsymbol{a}+\boldsymbol{b}) \\
(\mathbf{m g} / \mathbf{g})\end{array}$ & Chl $\boldsymbol{a} / \boldsymbol{b}$ & Carotenoid \\
\hline $\mathrm{WT}^{1}$ & $0.38 \pm 0.02$ & $0.09 \pm 0.01$ & $0.46 \pm 0.03$ & $4.36 \pm 0.19$ & $0.14 \pm 0.01$ \\
$\mathrm{MT}^{2}$ & $0.07 \pm 0.00^{* *} 3$ & $0.03 \pm 0.00^{* *}$ & $0.11 \pm 0.00^{* *}$ & $2.17 \pm 0.33^{* *}$ & $0.15 \pm 0.01$ \\
\hline
\end{tabular}

${ }^{1}$ WT means wild-type T. grandis 'Merrillii'; ${ }^{2}$ MT means yellow leaf mutant-type T. grandis 'Merrillii'; ${ }^{3}$ Each value is mean $\pm \operatorname{SE}(n=3),{ }^{* *}$ indicates a significant difference at $p<0.05$.

\subsection{Analysis of PF, DF, and MR Kinetics}

The results in Figure 2A show that the yellow leaf mutants significantly changed the OJIP curve of the T. grandis 'Merrillii' leaves. The relative fluorescence intensities $F_{0}$ of point $\mathrm{O}, \mathrm{F}_{\mathrm{J}}$ of point $\mathrm{J}, \mathrm{F}_{\mathrm{I}}$ of point $\mathrm{I}$, and $\mathrm{F}_{\mathrm{P}}$ of point $\mathrm{P}$ all decreased. In DF induction kinetics (Figure 2B), the fast phase occurs until $250 \mathrm{~ms}$ and includes the $\mathrm{I}_{1}(7 \mathrm{~ms})$ and $\mathrm{I}_{2}(50 \mathrm{~ms})$ peaks, which also coincide with PF's OJIP transient stage. Meanwhile, the values of $\mathrm{I}_{1}$ and $\mathrm{I}_{2}$ decreased in the mutant-type leaves. The DF decay kinetics at $\mathrm{I}_{1}$ (Figure $2 \mathrm{C}$ ) showed a significant decrease in the mutant-type leaves. The shape of the $M R / M R_{O}$ kinetics in the mutant-type leaves of T. grandis 'Merrillii' demonstrated obvious changes (Figure 2D). The time of occurrence of the minimum value of the $M R / M R_{O}$ kinetics in the mutant-type leaves appeared earlier than it did in the wild-type leaves. The lowest $M R / M R_{O}$ kinetic points for the wild- and mutant-type leaves of T. grandis 'Merrillii' occurred in the range of 15-20 ms.

The PSI parameters were derived from $M R / M_{O}$ transients (Table 2), the maximum PSI oxidation rate $\left(\mathrm{V}_{\mathrm{PSI}}\right)$ of the mutant-type leaves in the range of $0.7-20 \mathrm{~ms}$ decreased faster than that in the wild-type leaves. The maximum PS reduction rate ( $\mathrm{V}_{\text {PSII-PSI }}$ ) of the mutanttype leaves in the range of 20-300 ms increased faster than that of the wild-type leaves. The PF parameters for the mutant-type T. grandis 'Merrillii' leaves were significantly influenced as shown in Table 3. In the mutant-type leaves of T. grandis 'Merrillii', the parameters $\mathrm{F}_{\mathrm{v}} / \mathrm{F}_{\mathrm{m}}, \psi_{\mathrm{o}}, \gamma_{\mathrm{RC}}, \varphi_{\mathrm{Eo}}, \varphi_{\mathrm{Ro}}$, and $\mathrm{RC} / \mathrm{CS}_{\mathrm{M}}$ all decreased significantly, the parameters $\delta_{\mathrm{Ro}}$ and $\mathrm{RC} / \mathrm{CS}_{0}$ did not show any significant change, while $\varphi_{\text {Do }}$ increased significantly.

Table 2. Parameters derived from the modulated $820 \mathrm{~nm}$ reflection (MR/MRo) of the mutant-type and wild-type Torreya grandis 'Merrillii'.

\begin{tabular}{cccc}
\hline Torreya grandis & $\left.\mathbf{V}_{\text {PSI }}{ }^{\mathbf{3}} \mathbf{( 0 . 7 - 2 0 ~} \mathbf{~ m s}\right)$ & $\left.\mathbf{V}_{\text {PSII-PSI }}{ }^{\mathbf{4}} \mathbf{( 2 0 - 3 0 0 ~} \mathbf{~ m s}\right)$ & $\mathbf{V}_{\text {PSII }}{ }^{\mathbf{5}}$ \\
\hline $\mathrm{WT}^{1}$ & $0.193 \pm 0.01$ & $0.015 \pm 0.001$ & $0.208 \pm 0.014$ \\
$\mathrm{MT}^{2}$ & $0.207 \pm 0.003^{* *}$ & $0.017 \pm 0.001^{* *}$ & $0.224 \pm 0.004^{* *} 6$ \\
\hline
\end{tabular}

${ }^{1}$ WT means wild-type T. grandis 'Merrillii'; ${ }^{2} \mathrm{MT}$ means yellow leaf mutant-type T. grandis 'Merrillii'; ${ }^{3} \mathrm{~V}_{\mathrm{PSI}}$ : maximum slope decrease of $\mathrm{MR} / \mathrm{MR}_{\mathrm{o}} ;{ }^{4} \mathrm{~V}_{\mathrm{PSII}} \mathrm{PSI}$ : maximum slope increase of $\mathrm{MR} / \mathrm{MR}_{\mathrm{o}} ;{ }^{5} \mathrm{~V}_{\mathrm{PSII}}=\mathrm{V}_{\mathrm{PSI}}+\mathrm{V}_{\mathrm{PSII}}$ PSI ; ${ }^{6}$ Each value is mean $\pm \operatorname{SE}(n=3),{ }^{* *}$ indicates a significant difference at $p<0.05$. 


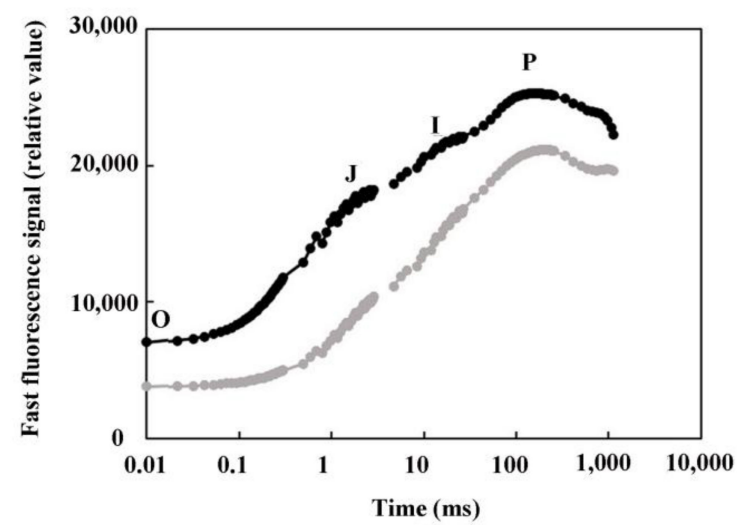

A

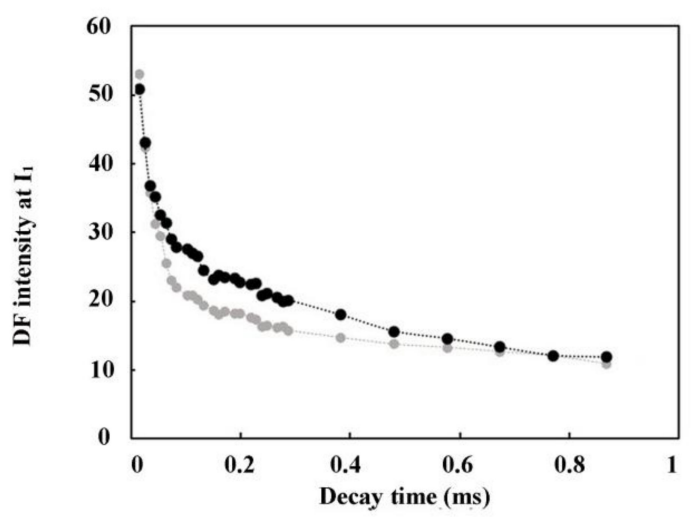

C

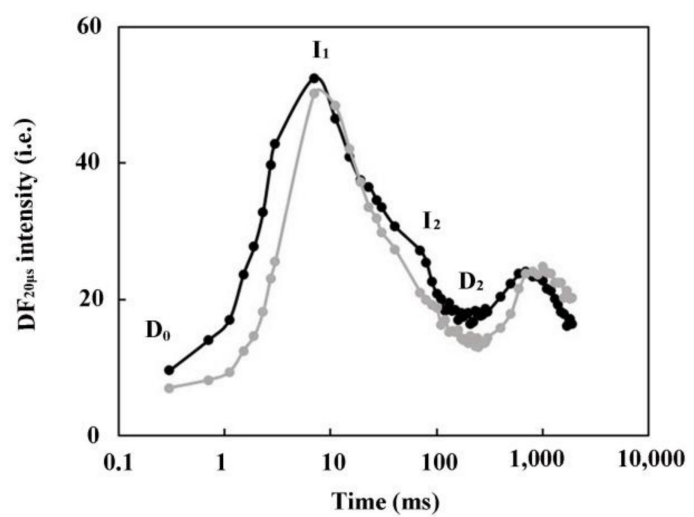

B

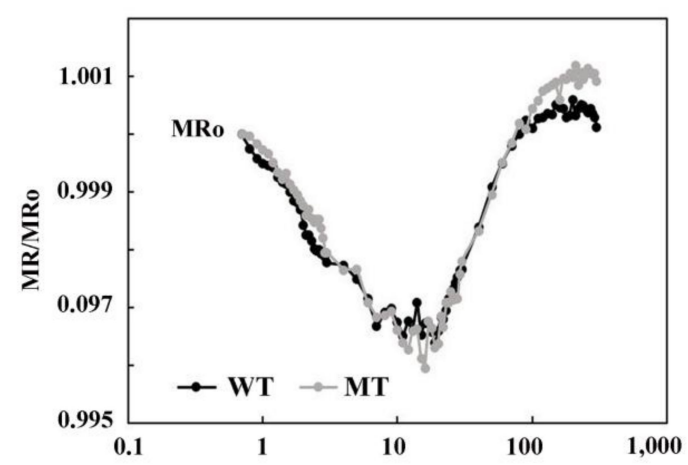

D

Figure 2. The PF, DF, and MR kinetics in leaves of MT and WT Torreya grandis 'Merrillii'. Each curve is the average of three replicates. WT means wild type; MT means yellow leaf mutant type; (A), Prompt chlorophyll $a$ fluorescence (PF). The signals were plotted on a logarithmic time scale. The signals used were fluorescence intensity at $20 \mu \mathrm{s} \equiv \mathrm{F}_{\mathrm{o}}$; at $3 \mathrm{~ms} \equiv \mathrm{F}_{\mathrm{J}}$ and at $30 \mathrm{~ms} \equiv \mathrm{F}_{\mathrm{I}}$; maximum fluorescence intensity, $\mathrm{F}_{\mathrm{P}}=\mathrm{F}_{\mathrm{m}}$. (B), Delayed chlorophyll $a$ fluorescence. The signals were plotted on a logarithmic time scale. (DF). (C), The decay kinetics of DF at the characteristic maxima $\mathrm{I}_{1}(7 \mathrm{~ms})$. The signals were plotted on a linear time scale. (D), Modulated $820 \mathrm{~nm}$ reflection $\left(\mathrm{MR} / \mathrm{MR}_{\mathrm{O}}\right)$. The signals were plotted on a logarithmic time scale.

Table 3. Parameters derived from prompt chlorophyll $a$ fluorescence transients in leaves of mutanttype and wild-type Torreya grandis 'Merrillii'.

\begin{tabular}{|c|c|c|c|c|c|c|c|c|c|}
\hline $\begin{array}{l}\text { Torreya } \\
\text { grandis }\end{array}$ & $F_{v /} F_{m}^{3}$ & $\Psi o^{4}$ & $\delta_{\mathbf{R o}^{5}}{ }^{5}$ & $\gamma_{\mathrm{RC}}{ }^{6}$ & $\varphi_{\text {Eo }}{ }^{7}$ & $\varphi_{\mathbf{R o}}{ }^{8}$ & $\varphi_{\text {Do }}{ }^{9}$ & $\underset{10}{\mathrm{RC} / \mathrm{CS}_{0}}$ & $\mathrm{RC} / \mathrm{CS}_{\mathrm{M}}$ \\
\hline $\mathrm{WT}^{1}$ & $\begin{array}{c}0.82 \pm \\
0.01\end{array}$ & $\begin{array}{c}0.70 \pm \\
0.04\end{array}$ & $\begin{array}{c}0.35 \pm \\
0.02\end{array}$ & $\begin{array}{c}0.50 \pm \\
0.00\end{array}$ & $\begin{array}{c}0.57 \pm \\
0.04\end{array}$ & $\begin{array}{c}0.20 \pm \\
0.03\end{array}$ & $\begin{array}{l}0.18 \pm \\
0.01^{* *}\end{array}$ & $\begin{array}{c}3804 \pm \\
240\end{array}$ & $\begin{array}{c}21,305 \pm \\
2004\end{array}$ \\
\hline $\mathrm{MT}^{2}$ & $\begin{array}{l}0.73 \pm \\
0.06^{* *}\end{array}$ & $\begin{array}{l}0.43 \text { 士 } \\
0.09^{* *}\end{array}$ & $\begin{array}{c}0.41 \pm \\
0.09\end{array}$ & $\begin{array}{l}0.32{ }^{*} \\
0.06^{* *}\end{array}$ & $\begin{array}{l}0.322^{*} \\
0.09^{* *}\end{array}$ & $\begin{array}{l}0.12 \pm \\
0.02^{* *}\end{array}$ & $\begin{array}{c}0.27 \pm \\
0.06\end{array}$ & $\begin{array}{c}3149 \pm \\
254\end{array}$ & $\begin{array}{l}12,146 \pm \\
2875^{* *} 11\end{array}$ \\
\hline
\end{tabular}

${ }^{1}$ WT means wild type; ${ }^{2}$ MT means yellow leaf mutant type; ${ }^{3} F_{v} / F_{m}$, maximal quantum efficiency of PSII; ${ }^{4} \mathrm{~V}_{\mathrm{J}}$ the relative variable fluorescence at the J-step; $\psi_{\mathrm{o}}$, a trapped exciton moves an electron into the electron transport chain beyond $\mathrm{Q}_{\mathrm{A}}{ }^{-}$at $\mathrm{t}=\mathrm{F}_{\mathrm{o}} ;{ }^{5} \delta_{\mathrm{Ro}}$, efficiency required for an electron to be transferred from reduced carriers between the two photosystems to the PSI end acceptors. ${ }^{6} \gamma_{\mathrm{RC}}$, a given chlorophyll $a$ molecule that functions as the PSII reaction center. ${ }^{7} \varphi_{\mathrm{Eo}}$, quantum efficiency of electron transfer at $\mathrm{t}=\mathrm{F}_{\mathrm{o}} .{ }^{8} \varphi_{\mathrm{Ro}}$, quantum yield for reduction of the terminal electron acceptors on the PSI acceptor side. ${ }^{9} \varphi_{\text {Do }}$, quantum yield for energy dissipation at $\mathrm{t}=\mathrm{F}_{\mathrm{O}}$ ${ }^{10} \mathrm{RC} / \mathrm{CS}_{\mathrm{o}}$ and $\mathrm{RC} / \mathrm{CS}_{\mathrm{m}}$, the $\mathrm{Q}_{\mathrm{A}}{ }^{-}$reducing active $\mathrm{RCs}$ per $\mathrm{CS}\left(\mathrm{at} \mathrm{t}=\mathrm{F}_{\mathrm{o}}\right.$; at $\left.\mathrm{t}=\mathrm{F}_{\mathrm{m}}\right) .{ }^{11}$ Each value is the mean $\pm \mathrm{SE}$ $(n=3),{ }^{* *}$ indicates a significant difference at $p<0.05$. 
The absorbed energy fluxes are shown in Figure 3. The ABS/RC, $\mathrm{TR}_{0} / \mathrm{RC}$, and $\mathrm{DI}_{0} / \mathrm{RC}$ value were all increased significantly in the leaves of the mutant-type T. grandis 'Merrillii', while $\mathrm{ET}_{0} / \mathrm{RC}$ and $\mathrm{RE}_{0} / \mathrm{RC}$ had no significant differences between the yellow and green leaves of T. grandis 'Merrillii' (Figure 3A). When all of these values were determined at the maximum (index $\mathrm{M}$ ) chlorophyll fluorescence levels, the $\mathrm{ABS} / \mathrm{CS}_{\mathrm{M}}$ and $\mathrm{TR}_{0} / \mathrm{CS}_{\mathrm{M}}$ achieved demonstrated no significant difference between the wild-type and mutant-type T. grandis 'Merrillii'. The $\mathrm{DI}_{0} / \mathrm{CS}_{\mathrm{M}}$ increased significantly in the leaves of mutant-type $\mathrm{T}$. grandis 'Merrillii', while $\mathrm{ET}_{0} / \mathrm{CS}_{\mathrm{M}}$ and $\mathrm{RE}_{0} / \mathrm{CS}_{\mathrm{M}}$ were both significantly decreased in the leaves of mutant-type T. grandis 'Merrillii' (Figure 3B).
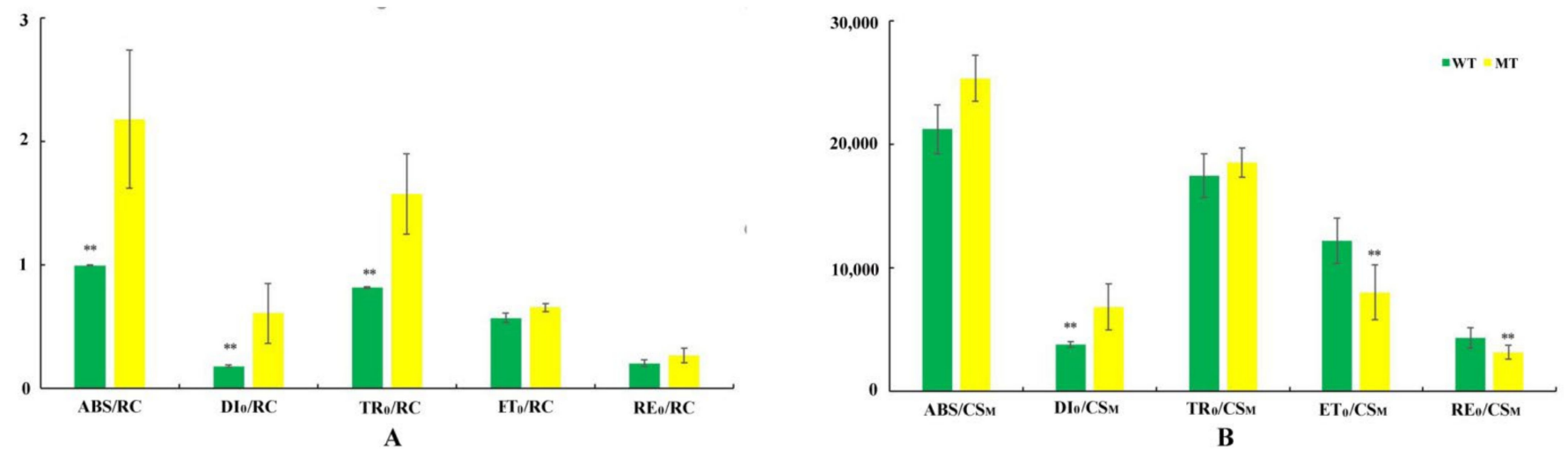

Figure 3. Energy flux models for the leaf samples of mutant-type and wild-type leaves under the same physiological conditions. The relative value of each parameter is proportional to the column height of the column charts. Graph (A) represents the specific activity on a single PSII reaction center (RC) basis. Graph (B) represents the specific activity on cross section (CS) basis. Bars represent the standard deviation of three repeats $(n=3) ;{ }^{* *}$ indicates a significant difference at $p<0.05$.

\subsection{Overview of the Transcriptome Data by RNA-Seq Analysis}

RNA-Seq data were generated from the leaves of wild-type and mutant-type T. grandis 'Merrillii', which were sequenced in three biological replicates. Excluding the adapters, lowquality regions (reads in which the base number of $Q_{\text {phred }}<=20$ accounts for more than 50\% of the whole read length), and all possible contamination, six paired-end libraries obtained more than $64.62 \mathrm{~Gb}$ of clean data, attaining an average of 143 million clean reads per library with Q30 > 94.06\% and a GC percentage of 43.12-43.53\% (Table S2). All of the reads were deposited in the NCBI Sequence Read Archive under accession number PRJNA687396. As T. grandis 'Merrillii' does not have a reference genome sequence, Trinity [31] was used with the min_kmer_cov set to 2 by default and all other parameters set to the de novo assembly of all the clean reads as default, as shown in Figure S1. The Pearson's correlation coefficient $(\mathrm{R})$ between the biological replicates was $>0.75$ (Figure S2). More than $80 \%$ of the reads were mapped back to the assembled transcripts in the six samples (Table S3) using RSEM software [32]. Nr, Nt, Pram, KOG, KO, Swiss-prot, and GO databases were used to annotate all unigenes, and a total of 89,955 unigenes were successfully annotated with gene information (Table S4).

\subsection{Pairwise Comparisons of the Transcriptomes between Wild Type and Mutant Type of T. grandis 'Merrillii'}

The comparisons of the unigenes annotated in the leaves of wild-type and mutanttype T. grandis 'Merrillii' are shown in Figure S3. A total of 39,986 (48\%) unigenes were annotated in all the samples. To determine the gene expression response to the different leaf colors, differentially expressed genes (DEGs) in the pairwise comparison between the wild-type (WT) and mutant-type (MT) leaves were identified using the combined criteria $\log 2$ fold-change in the range between $\geq+1.0$ and $\leq-1.0$ and a corrected Padj value $<0.05$. In total, we identified 10,789 DEGs in the comparison (Table S5). In total, 9798 unigenes 
were upregulated and 991 unigenes were downregulated in the wild-type compared to the mutant-type leaves (Figure S4).

GO and KEGG pathway enrichment analyses were applied to explore the functions of the DEGs. The GO annotation suggested that the unigenes were annotated with 60 GO terms (Figure S5), in which more than 4000 unigenes were annotated in the 'binding', 'membrane', and 'protein binding' terms. The results indicated that these terms play crucial roles in the response of T. grandis 'Merrillii' to different leaf colors. A total of 117 pathways were categorized from the comparison in the KEGG pathway enrichment analysis. Among them, the top 20 enriched pathways (based on q values) in the comparison are shown in Figure S6. These pathways were closely related to 'terpenoid backbone biosynthesis', 'ribosome biogenesis in eukaryotes', 'ubiquitin mediated proteolysis', and 'regulation of autophagy'. The significantly enriched terms had no direct relationship with leaf color in $T$. grandis 'Merrillii'.

\subsection{DEGs Involved in Photosynthesis and Photosynthetic Pigment Metabolism Associated Pathways}

The metabolic pathways directly related to leaf color were analyzed, and these included the photosynthetic and the porphyrin and chlorophyll biosynthesis pathways. Three DEGs were clustered in the photosynthetic pathway based on the KO database from the comparison (MT vs. WT) and matched three genes, including the PSII P600 reaction center D1 protein $(P s b A)$, PSII cytochrome b559 subunit alpha $(P s b E)$, and ferredoxin-NADP ${ }^{+}$ reductase $(\mathrm{PetH}) . P s b A$ and $P s b E$ encode the D1 protein and $\beta$ subunits of cytochrome b559 in PSII, respectively. PetH encodes the synthesis of the photosynthetic electron carrier ferredoxin-NADP ${ }^{+}$reductase (FNR). The expression levels of the unigenes, including PsbA (Cluster-41647.24000) and PsbE (Cluster-41647.10995), in the yellow leaves of T. grandis 'Merrillii' were higher than those in green leaves, while the expression level of the PetH (Cluster-41647.15332) gene in the yellow leaves was lower than that in the green leaves.

Sixteen DEGs were clustered in the porphyrin and chlorophyll metabolic pathway based on the KO database developed from the comparison (MT vs. WT) and matched 12 genes, including hydroxyl methylbilane synthase $($ hemC), uroporphyrinogen decarboxylase (hemE), coproporphyrinogen III oxidase (hemF), protoporphyrin/coproporphyrin ferrochelatase $($ hem $H)$, protoporphyrinogen/coproporphyrinogen III oxidase (hem $Y$ ), cytochrome c oxidase assembly protein subunit $15(\mathrm{cta} A)$, heme o synthase (ctaB), glutamyltRNA synthetase ( $g l t X)$, cytochrome c heme-lyase (HCCS), glucuronosyltransferase (UGT), light-independent protochlorophyllide reductase subunit L (chlL), and geranylgeranyl diphosphate/geranylgeranyl bacteriochlorophyllide, a reductase. Among these genes, hemC, hemE, hemF, hem Y, gltX, and chlL are involved in chlorophyll synthesis, and hemH, HCCS, and hemH are involved in cytochrome c synthesis. The expression levels of the genes hemC (Cluster-41647.4613), hemE (Cluster-29883.0), hemF (Cluster-17955.0), hem Y (Cluster31222.0), gltX (Cluster-41647.33265, Cluster-41647.4114), hemH (Cluster-41647.8307), and HCCS (Cluster-40119.0) were significantly lower in the yellow leaves than they were in the green leaves of T. grandis 'Merrillii', while the expression levels of the genes hemE (Cluster41647.18465), gltX (Cluster-41647.32963), and chlL (Cluster-41647.30461) were higher in the yellow leaves than they were in the green leaves. The expression levels of the unigenes mentioned above are presented in Figure 4. 


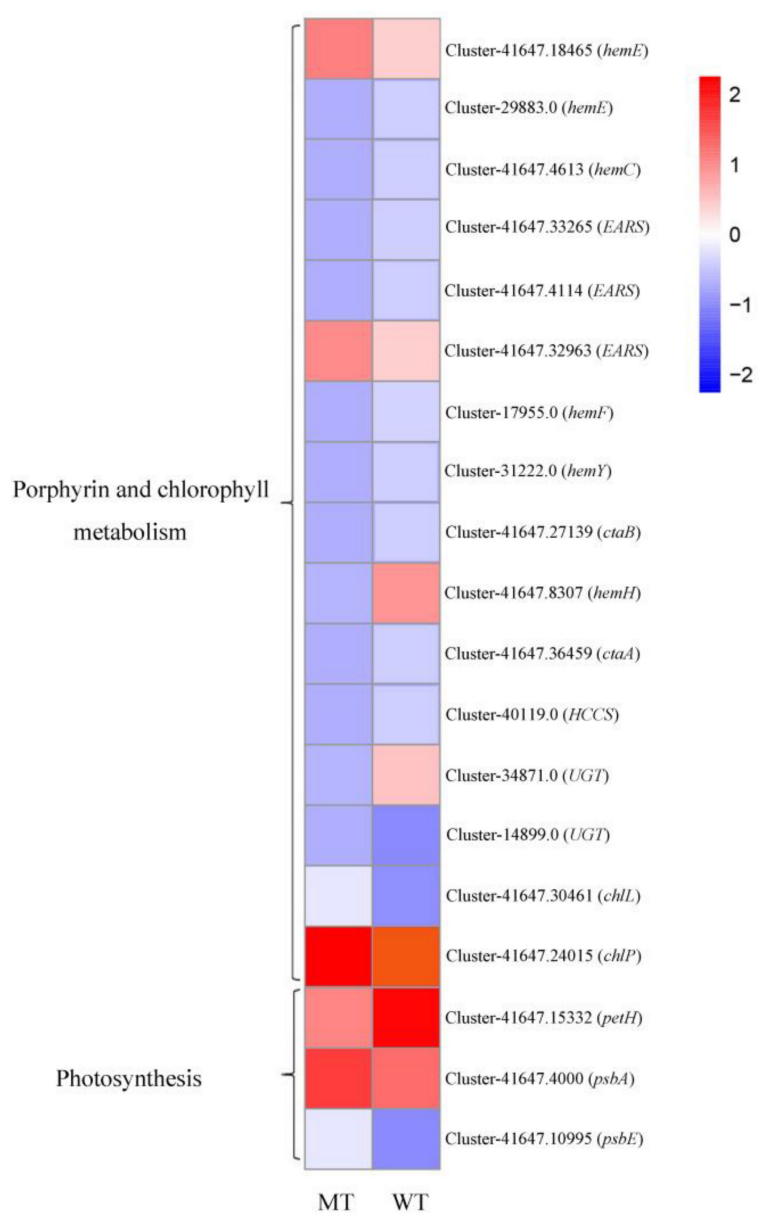

Figure 4. Heat maps of the differentially expressed unigenes involved in related pathways in leaves of mutant-type and wild-type Torreya grandis 'Merrillii'. WT means wild type; MT means yellow leaf mutant type; the transcriptome data (FPKM) were used to create the heat maps.

\subsection{Validation of Transcription Data Using $q R T-P C R$}

Differential expression analysis of RNA-seq was done using qRT-PCR technique, and six DEGs were used for the RT-PCR analysis. The expression tendency of these six genes by qRT-PCR was consistent with the data of RNA-Seq. (Figure 5), suggesting that the transcriptome data were highly reliable. 


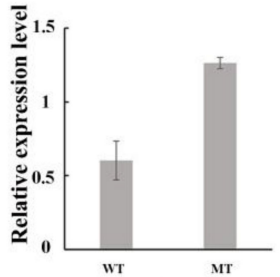

A

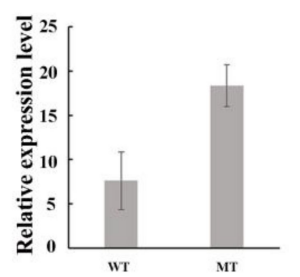

G

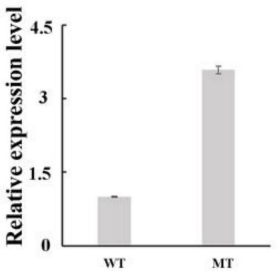

B

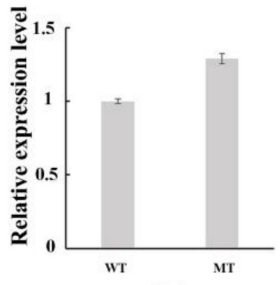

$\mathbf{H}$

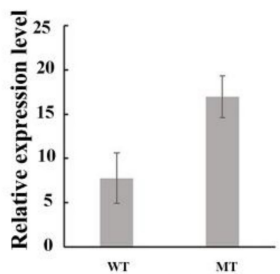

C

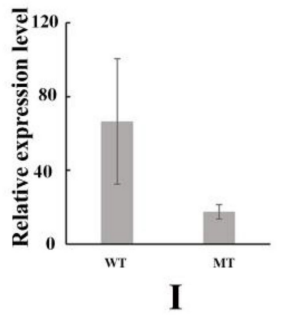

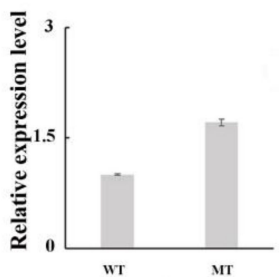

D

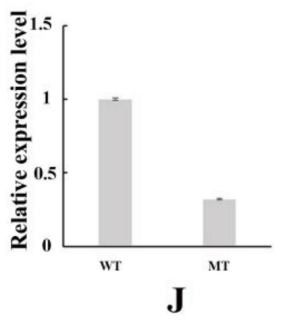

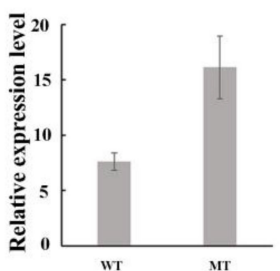

$\mathbf{E}$

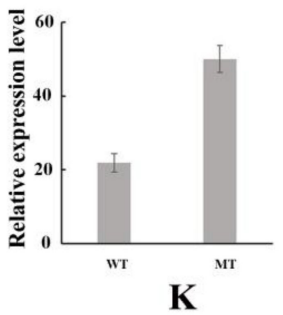

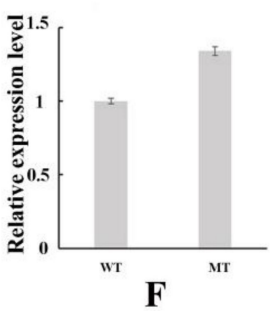

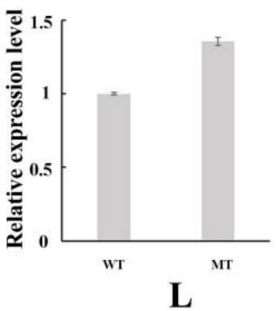

Figure 5. qRT-PCR confirmation of the DEGs identified by the transcriptome analysis. The relative expression level of each gene was expressed as the fold-change relative to the internal reference gene cyclophilin. WT means wild type; MT means yellowleaf mutant type; (A,B), unigene ID: Cluster-41647.30461. The relative expression of chlL. (C,D), unigene ID: Cluster-41647.18465. The relative expression of hemE. (E,F), unigene ID: Cluster-41647.32963. The relative expression of EARS. $(\mathbf{G}, \mathbf{H})$, unigene ID: Cluster-41647.29473. The relative expression of VDE. (I,J), unigene ID: Cluster41647.15332. The relative expression of petH. (K,L), unigene ID: Cluster-41647.24000. The relative expression of $p s b A$. (A,C,E,G,I,K), the data of RNA-Seq. (B,D,F, $\mathbf{H}, \mathbf{J}, \mathbf{L})$, the data of qRT-PCR. The qPCR data of each sample with three biological and three technical replicates.

\section{Discussion}

\subsection{Chlorophyll Deficiency Mutant}

The etiolation phenomenon commonly occurs in plants, and has been systematically studied in crops and model plants. These mutants with yellow leaves are ideal material for further study on topics such as the development and function of chloroplasts and genetics and breeding [5,11]. Previous studies have reported that the composition and content of pigments in mesophyll cells are directly related to the formation of yellow leaf color in plants $[12,21,22]$. The contents of chlorophyll and carotenoid typically decrease simultaneously in the yellow leaves of woody plants [33,34]. In this study, the yellow leaf color variation of T. grandis 'Merrillii' was a chlorophyll-deficit mutant, and the carotenoid content did not differ between the green and yellow leaves. The yellow leaf mutant used in this study was obtained from a natural yellow leaf bud mutation, which is the first chlorophyll-deficit mutant identified in T. grandis 'Merrillii'. The $\mathrm{Chl} a / b$ value was lower in the leaves of T. grandis 'Merrillii' with yellow leaves than it was with green leaves, which means that the deficiency of $\mathrm{Chl} a$ is more severe than that of $\mathrm{Chl} b$ and, thereby, inconsistent with previous studies. Usually the Chl $a / b$ of wild-type leaves is higher than it is with mutant-type yellow leaves $[22,35,36]$, leading to poor light harvesting ability and an underdeveloped light harvesting antenna system [37]. Our results found that the yellow leaf mutant of T. grandis 'Merrillii' was different from the etiolation mutant of other species, indicating that the structure and stability of the light-harvesting complexes and photosynthetic reaction centers or the size of the photosynthetic antenna may be changed [35-38]. This yellow leaf mutant is excellent material for studying chlorophyll synthesis, the structure of photosynthetic systems, and gene functions and their regulatory mechanisms in woody plants.

\subsection{The Leaf Color Response of T. grandis 'Merrillii' Influences Chlorophyll Fluorescence}

Photosynthetic electron transfer occurs in the thylakoid membranes of chloroplasts, and are related to PSI, PSII, and photosynthetic electron carriers [10,13-15]. Chlorophyll 
fluorescence is usually measured to investigate photosynthetic electron transfer [16-18]. This study measured the photosynthesis induction kinetics of PF, DF, and MR between green and yellow leaves of T. grandis 'Merrillii'. In the yellow leaves of T. grandis 'Merrillii', PF kinetics changed significantly, and the signals $\left(\mathrm{F}_{\mathrm{O}}, \mathrm{F}_{\mathrm{J}}, \mathrm{F}_{\mathrm{I}}\right.$, and $\left.\mathrm{F}_{\mathrm{P}}\right)$ decreased sharply. A previous study reported that decrease in the $\mathrm{F}_{\mathrm{P}}$ signal may be related to an increase in nonradiative heat dissipation of the PSI antenna pigment, shrinking of the antenna pigment [39], a decrease in the number of active PSI reaction centers [40], a damaged PSI receptor side [18], or denatured and degraded photosynthetic pigment-protein complexes [38-40]. In the yellow leaves of T. grandis 'Merrillii', both the DF kinetic values decreased (Figure 2B,C), suggesting that the PSII electrons had a reduced ability to pass downstream and regenerate the antenna pigment [16].

The chlorophyll $a$ fluorescence parameters in the leaves of mutant-type and wild-type Torreya grandis 'Merrillii' were used to illustrate photosynthetic energy and electron transfer. $F_{v} / F_{m}$ represents the latent capacity of PSII quantum efficiency, and is widely used as an indicator of the photochemical activity of photosynthetic mechanism. $F_{v} / F_{m}$ is considered to be an indicator of photoinhibition [41], and reflects the maximum quantum yield for primary photochemistry [42]. In this study, the ratio of $\mathrm{Chl} a / b$ in mutant-type $T$. grandis 'Merrillii' is lower than it is in wild-type plants (Table 1), which leads to stronger lightharvesting ability and a better light-harvesting antenna system. Meanwhile, the $F_{v} / F_{m}$ value (Table 3) in the yellow leaves of mutant-type T. grandis 'Merrillii' decreased. ABS/RC values increased more in the leaves of mutant-type T. grandis 'Merrillii' than they did in wild-type leaves (Figure 3), suggesting that the antenna size became larger relative to P680 in the yellow leaves of T. grandis 'Merrillii' [43].

The $\varphi_{\mathrm{Ro}}, \varphi_{\mathrm{Eo}}, \psi_{0}$, and $\gamma_{\mathrm{RC}}$ values decreased significantly in the mutant-type of $T$. grandis 'Merrillii' compared to the green leaves (Table 3, Figure 3), indicating a decrease in $P Q$ exchange capacity at the $\mathrm{Q}_{\mathrm{B}}$ site and in $\mathrm{PQH}_{2}$ reoxidation capacity [44], and a decrease in the quantum yield for electron transfer both from $\mathrm{Q}_{\mathrm{A}}{ }^{-}$to the electron transport chain beyond $\mathrm{Q}_{\mathrm{A}}{ }^{-}$and from $\mathrm{Q}_{\mathrm{A}}{ }^{-}$to the reduction of the end electron acceptors on the acceptor side of PSI in the yellow leaves of T. grandis 'Merrillii'. The values of $\mathrm{ET}_{0} / \mathrm{CS}_{\mathrm{M}}$ and $\mathrm{RE}_{0} / \mathrm{CS}_{\mathrm{M}}$ were significantly lower in mutant-type T. grandis 'Merrillii' with yellow leaves compared to green leaves, and maybe both the size of the functional antenna and the exciton specific rate captured by the open RCS were reduced [45]. The decrease in $\mathrm{ET}_{0} / \mathrm{CS}_{\mathrm{M}}$ and $\mathrm{RE}_{0} / \mathrm{CS}_{\mathrm{M}}$ values and increase in $\mathrm{DI}_{0} / \mathrm{CS}_{\mathrm{M}}$ are proposed to be due to the thermal inactivation of RCs [46]. These indicated that PSII activity limited linear electron transport in the yellow leaves of T. grandis 'Merrillii'.

The changes in the redox states of P700 and PC were reflected by the changes in

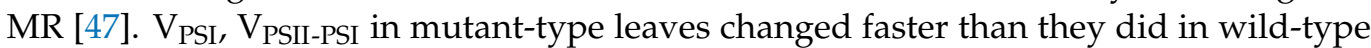
plants (Table 2). This can be interpreted as the oxidation and reduction ability of PSI and PC, which increases when leaves mutate in color and become yellow [16]. Meanwhile, the value of $\delta_{\text {Ro }}$ has no significant difference in the yellow leaf mutant-type T. grandis 'Merrillii' compared to green leaves. These effects are inconsistent with the decrease in PSII activity in the leaves of T. grandis 'Merrillii', as analyzed above using the PF signal. These results illustrate that PSI activity was appreciably stimulated in the yellow leaves of T. grandis 'Merrillii'. When PSII activity reduced, PSI activity increased, which could have been caused by the enhancement in cyclic electron flows [48].

Therefore, our results suggest that the potential quantum efficiency of PSII in yellow leaf mutant-type T. grandis 'Merrillii' decreased and damaged the photosynthetic apparatus, resulting in the inactivation of photosynthetic reaction centers and the degradation of D1 protein $[41,42,49,50]$. The photosynthetic electron carriers were blocked in the electron transfer from $\mathrm{Q}_{\mathrm{A}}{ }^{-}$to the electron transport chain beyond $\mathrm{Q}_{\mathrm{A}}{ }^{-}$and the electron transfer from $\mathrm{Q}_{\mathrm{A}}{ }^{-}$to the reduction of terminal electron acceptors on the acceptor side of PSI in the leaves of the yellow leaf mutant of T. grandis 'Merrillii'. These results indicate that the cyclic electron flows around PSI may be a photo-protective mechanism of the yellow 
leaf mutant-type T. grandis 'Merrillii', which can help thylakoid membranes cope with the chlorophyll deficit and decreased linear electron transport of PSII.

\subsection{The Leaf Color Response of T. grandis 'Merrillii' Influences Chlorophyll Synthesis}

High-throughput transcriptome sequencing technology has been applied in several studies related to the molecular formation of yellow leaves in woody plants. One study reported that the molecular mechanism for the formation of the yellow leaf mutation in different woody species differed by identifying the expression level of the unigenes involved in chlorophyll metabolism, such as in C. sinensis 'Baijiguan' [21] and L. indica [33,34]. An example is the yellow leaf mutant of L. indica, which is caused by a disruption in coproporphyrinogen III oxidase (CPO) biosynthesis [34]. In the present study, 12 DEGs in the pairwise comparison between wild type (WT) and the yellow leaf mutant type (MT) were identified in 'porphyrin and chlorophyll metabolism' using the combined criteria of the $\log 2$ fold-change in the range between $\geq+2.0$ and $\leq-2.0$ and a corrected Padj value $<0.05$. These 12 DEGs matched 10 genes (hemC, hemE, hemF, hemH, hem Y, ctaA, ctaB, gltX, $H C C S$, and UGT), in which six unigene annotations in five genes (including hem $C$, hemE, hemF, hem Y, gltX) were involved in chlorophyll synthesis (Figure 6A). In higher plants, the level of Glu TR mRNA ( $g l t X)$ is positively correlated with chlorophyll synthesis [51]. Compared with green leaves, the expression of genes hemC, hemE, hemF, hem Y, and gltX in yellow leaves of T. grandis 'Merrillii' were significantly downregulated, possibly because the chlorophyll synthesis precursor protoporphyrin IX had decreased, and then led to chlorophyll content decrease. Additionally, the unigenes involved in the synthesis of heme A and cytochrome were downregulated, as shown in Figure 6A. The effects of phytochrome and cytochrome on the formation of yellow leaves will be studied in future research.
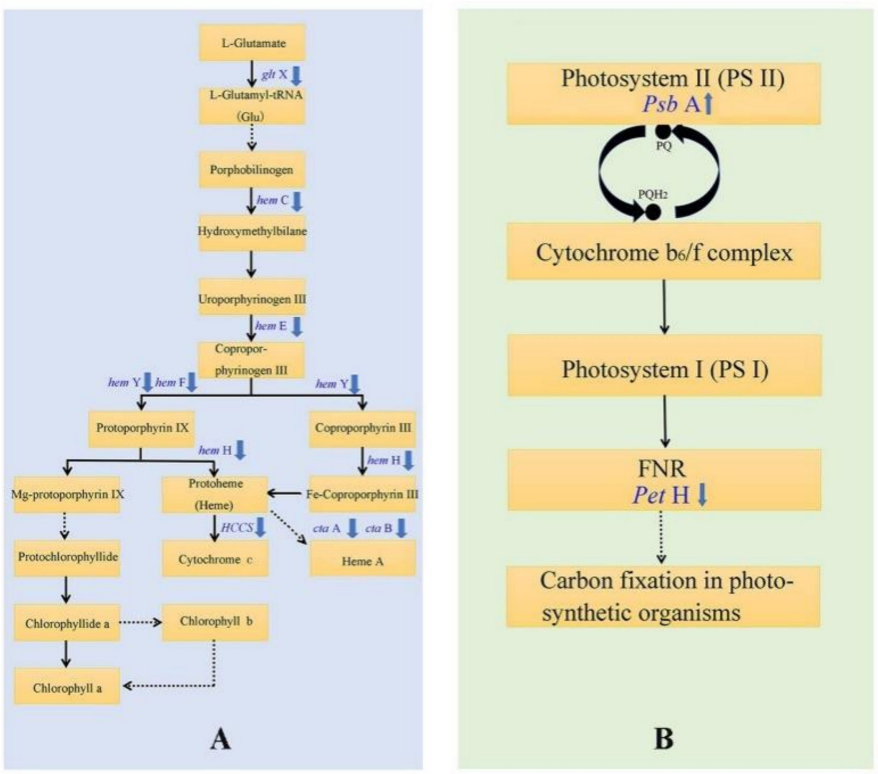

Figure 6. Genes involved in pathways related to the yellow leaf mutant of Torreya grandis 'Merrillii'. (A), The porphyrin and chlorophyll metabolic pathway; (B), the photosynthetic pathway.

Previous studies have shown that chlorophyll and carotenoid content is the proximate cause of yellow leaves [52]. This study determined that the chlorophyll content decreased, and the expression level of genes-related chlorophyll synthesis was downregulated in the yellow leaves of T. grandis 'Merrillii', while the carotenoid content and its synthesis displayed no significant changes compared to green leaves. Therefore, the leaf color mutation mechanism is mainly related to low chlorophyll synthesis efficiency and lower amounts of chlorophyll. Meanwhile, the PSII ability reduced, and the effective dissipation of excess 
excitation energy $\left(\mathrm{DI}_{0} / \mathrm{CS}_{\mathrm{M}}, \mathrm{DI}_{0} / \mathrm{RC}, \varphi_{\mathrm{Do}}\right)$ increased, indicating that carotenoids play a protective role in the PSII of yellow leaves in T. grandis 'Merrillii' from light damage [53].

\subsection{The Leaf Color Response of T. grandis 'Merrillii' Influences Photosynthetic Electron Transfer}

The photosynthesis that occurs in chloroplasts is usually separated into light reactions (light dependent) and dark reactions (light independent reactions). In photochemical reactions, PSII strips electrons from the water using light energy and releases $\mathrm{O}_{2}$. Electrons are transferred through the electron transport chain, ultimately producing NADPH. A previous study reported that chlorophyll fluorescence parameters $\left(F_{v} / F_{m}\right)$ in the photochemical reactions of green leaves are significantly higher than those in yellow leaves [22], which was consistent with the results of this study. PF, DF, and MR have been used to investigate photosynthesis, especially the photochemical reaction in the leaves of plants [16-18]. This simultaneous measurement can collect and correlate complementary information for photosynthetic electron transport [19]. The present study found that the PF and DF were significantly lower, while MR was higher in yellow leaves than it was in the green leaves of T. grandis 'Merrillii' (Figure 2). Previous studies have shown that PF and DF predominantly emitted from antenna pigments of PSII, and MR, PF and DF kinetics depend on the redox state of the reaction center of PSI (P700) and PSII (P680) (Gao et al., 2014). Our study determined that the $F_{v} / F_{m}, \psi_{\mathrm{o}}, \gamma_{\mathrm{RC}}, \varphi_{\mathrm{Eo}}, \varphi_{\mathrm{Ro}}, \mathrm{RC} / \mathrm{CS}_{\mathrm{M}}, \mathrm{ET}_{0} / \mathrm{CS}_{\mathrm{M}}$, and $\mathrm{RE}_{0} / \mathrm{CS}_{\mathrm{M}}$ parameters in yellow leaves were significantly lower than in the green leaves of T. grandis 'Merrillii'. These parameters reflect the changes in electron transfer rate on the PSII receptor side [53]. In summary, PSII has different electron transfer capacities in the yellow and green leaves of T. grandis 'Merrillii'.

The expression of the PsbR gene (coding PSII 10-kDa protein) is blocked in the yellow leaves of C. sinensis, thus resulting in unstable PSII, abnormal chloroplast structure, and obstructed chlorophyll biosynthesis [21]. Thirty-seven unigenes associated with photosynthetic metabolism were identified based on the KEGG pathway in the yellow leaf mutant of L. indica [34]. However, only one DEG (ferredoxin-NADP ${ }^{+}$reductase, $P e t H$ ) was detected in the pairwise comparison between the yellow leaf samples (MT) and the control green leaf samples (WT) in the 'photosynthesis' metabolism when using the combined criteria $\mid \log 2$ fold-change $I \geq 1.0$ and a corrected Padj value $<0.05$ (Figure 6B). Expression of the PetH gene in the yellow leaves of T. grandis 'Merrillii' was significantly lower than it was in the green leaves. Interestingly, the expression of the PetH gene was upregulated in the yellow leaf color mutant of L. indica [34]. FNR is a photosynthetic electron carrier, catalyzing the terminal step of electron transport that is associated with PSI by transferring reducing equivalents from ferredoxin or flavodoxin to NADP ${ }^{+}$[54]. The expression of the PsbA in yellow leaves of T. grandis 'Merrillii' was significantly higher than that in green leaves. Our results considered that D1 protein degradation had occurred [39], which was consistent with the chlorophyll fluorescence parameter $\left(F_{v} / F_{m}\right)$ in this study.

\section{Conclusions}

Compared to wild type, the chlorophyll content decreased and chlorophyll synthesis was blocked in the yellow leaves of T. grandis 'Merrillii'. However, both carotenoid content and carotenoid synthesis demonstrated no significant changes between the green and yellow leaves of T. grandis 'Merrillii'. Further, PSII activity was reduced, PSI activity increased, and the effective dissipation of excess excitation energy $\left(\mathrm{DI}_{0} / \mathrm{CS}_{\mathrm{M}}, \mathrm{DI}_{0} / \mathrm{RC}, \varphi_{\text {Do }}\right)$ increased in the yellow leaves of T. grandis 'Merrillii' compared to the green leaves. These results indicate that PSI activity and carotenoids play a photoprotective role in the yellow leaves of T. grandis 'Merrillii' to cope with decreased chlorophyll content and reduced PSII activity. The yellow leaf mutation in T. grandis is excellent material for Torreya breeding and research related to photosynthesis and chlorophyll. Furthermore, our study identified multiple DEGs, offering a global view of etiolation in Torreya grandis, which will help understand the formation process of yellow leaf and accelerate the molecular breeding of Torreya grandis. 


\begin{abstract}
Supplementary Materials: The following supporting information can be downloaded at: https: / / www.mdpi.com/article/10.3390/cells11030431/s1, Figure S1: Assembly results in the leaves of mutant-type and wild-type Torreya grandis 'Merrillii'. Figure S2: Pearson's correlation coefficients between two biological replicates in the six samples. Figure S3: Venn diagram of the number of DEGs (Padj < 0.05) in the leaves of mutant-type and wild-type Torreya grandis 'Merrillii'. Figure S4: Volcano map of the DEGs in leaves of mutant-type and wild-type Torreya grandis 'Merrillii'. Figure S5: GO annotation classification frequencies in the leaves of mutant-type and wild-type Torreya grandis 'Merrillii'. Figure S6: KO category enrichment of up/down regulated DEGs in the leaves of mutant-type and wild-type Torreya grandis 'Merrillii'. Table S1: Upper and lower primer sequences of genes evaluated using qPCR experiments. Table S2: Summary of sequence analysis of six libraries. Table S3: Number of total clean reads of the six samples mapped to reference sequences. Table S4: Success rate statistics of transcript annotation using seven databases. Table S5: The expression values of transcript data in six samples.
\end{abstract}

Author Contributions: Conceptualization, J.S. and S.J.; methodology, X.Z. and X.L.; software, Z.D. and X.C.; validation, J.S., S.J. and X.H.; formal analysis, X.Z. and X.L.; investigation, J.S.; resources, S.J.; data curation, J.S. and S.J.; writing —original draft preparation and writing-review and editing, J.S. and S.J.; funding acquisition, S.J. All authors have read and agreed to the published version of the manuscript.

Funding: This research was funded by National Key Research and Development Program of China (2019YFE0118900), the National Natural Science Foundation of China (31971641), Project of State Key Laboratory of Subtropical Silviculture, Zhejiang A\&F University (ZY20180208, ZY20180308), and Jiyang College of Zhejiang A\&F University under Grant (RQ1911B07).

Institutional Review Board Statement: Not applicable.

Informed Consent Statement: Not applicable.

Data Availability Statement: Data Availability Statements in the "RNA-Seq Analysis" section. All reads used in this study were deposited in the NCBI Sequence Read Archive under accession number PRJNA687396.

Conflicts of Interest: The authors declare no conflict of interest.

\title{
References
}

1. Feng, T.; Cui, J.J.; Xiao, Z.B.; Tian, H.X.; Yi, F.; Ma, X. Chemical composition of essential oil from the peel of Chinese Orreya grandis Fort. Org. Chem. Int. 2011, 3, 187372. [CrossRef]

2. Chen, X.W.; Jin, H.B. Review of cultivation and development of Chinese torreya in China. For. Trees Livelihoods 2019, $28,68-78$. [CrossRef]

3. Wang, H.; Li, Y.; Wang, R.; Ji, H.; Su, X. Chinese Torreya grandis cv. merrillii seed oil affects obesity through accumulation of sciadonic acid and altering the composition of gut microbiota. Food Sci. Hum. Wellness 2022, 11, 58-67. [CrossRef]

4. Chen, X.; Chen, X. Variation of fruit size and its frequency distribution in chinese torreya. Int. J. Fruit Sci. 2020, 20, S1445-S1457. [CrossRef]

5. Ruppel, N.J.; Logsdon, C.A.; Whippo, C.W.; Kentaro, I.; Hangarter, R.P. A mutation in Arabidopsis seedling plastid development1 affects plastid differentiation in embryo-derived tissues during seedling growth. Plant Physiol. 2011, 155, 342-353. [CrossRef] [PubMed]

6. Liu, C.; Chang, A.; Du, C. Genetic, physiological and biochemical analysis of the formation of yellow-green leaf color of burley tobacco (Nicotiana tabacum). Int. J. Agric. Biol. 2016, 18, 192-197. [CrossRef]

7. Chen, H.; Cheng, Z.; Ma, X.; Wu, H.; Liu, Y.; Zhou, K.; Chen, Y.; Ma, W.; Bi, J.; Zhang, X.; et al. A knockdown mutation of yellow-green leaf2 blocks chlorophyll biosynthesis in rice. Plant Cell Rep. 2013, 32, 1855-1867. [CrossRef]

8. Kim, Y.-K.; Lee, J.-Y.; Cho, H.S.; Lee, S.S.; Ha, H.J.; Kim, S.; Choi, D.; Pai, H.-S. Inactivation of organellar Glutamyl- and seryl-tRNA synthetases leads to developmental arrest of chloroplasts and mitochondria in higher plants. J. Biol. Chem. 2005, 280, 37098-37106. [CrossRef]

9. $\quad$ Lee, S.; Kim, J.H.; Yoo, E.S.; Lee, C.H.; Hirochika, H.G. An Differential regulation of chlorophyll a oxygenase genes in rice. Plant Mol. Biol. 2005, 57, 805-818. [CrossRef]

10. Mochizuki, N.; Tanaka, R.; Grimm, B.; Masuda, T.; Moulin, M.; Smith, A.; Tanaka, A.; Terry, M. The cell biology of tetrapyrroles: A life and death struggle. Trends Plant Sci. 2010, 15, 488-498. [CrossRef]

11. Zhao, Y.; Wang, M.L.; Zhang, Y.Z.; Du, L.F.; Pan, T. A chlorophyll-reduced seedling mutant in oilseed rape, Brassica napus, for utilization in $\mathrm{F}_{1}$ hybrid production. Plant Breed. 2010, 119, 131-135. [CrossRef] 
12. Jiang, W.B.; Zhuang, M.; Han, H.Z.; Dai, M.S.; Hua, G.P. Progress on color emerging mechanism and photosynthetic characteristics of colored-leaf plants. Acta Hortic. Sin. 2005, 32, 352-358. [CrossRef]

13. Ishikawa, T.; Shigeoka, S. Recent advances in ascorbate biosynthesis and the physiological significance of ascorbate peroxidase in photosynthesizing organisms. Biosci. Biotechnol. Biochem. 2008, 72, 1143-1154. [CrossRef] [PubMed]

14. Asada, K. The water-water cycle in chloroplasts: Scavenging of active oxygens and dissipation of excess photons. Annu. Rev. Plant Physiol. Plant Mol. Biol. 1999, 50, 601-639. [CrossRef]

15. Hu, Y.; Zhang, Y.; Yu, W.; Hänninen, H.; Song, L.; Du, X.; Zhang, R.; Wu, J. Novel insights into the influence of seed sarcotesta photosynthesis on accumulation of seed dry matter and oil content in Torreya grandis cv. "Merrillii". Front. Plant Sci. 2018, 8, 2179. [CrossRef]

16. Strasser, R.J.; Tsimilli-Michael, M.; Qiang, S.; Goltsev, V. Simultaneous in vivo recording of prompt and delayed fluorescence and $820 \mathrm{~nm}$ reflection changes during drying and after rehydration of the resurrection plant Haberlea rhodopensis. Biochim. Biophys. Acta 2010, 1797, 1313-1326. [CrossRef]

17. Goltsev, V.; Zaharieva, I.; Chernev, P.; Kouzmanova, M.; Kalaji, H.M.; Yordanov, I.; Krasteva, V.; Aleksandrov, V.; Stefanov, D.; Allakhverdiev, S.; et al. Drought induced modifications of photosynthetic electron transport in intact leaves: Analysis and use of neural networks as a tool for a rapid non-invasive estimation. Biochim. Biophys. Acta 2012, 1817, 1490-1498. [CrossRef]

18. Oukarroum, A.; Goltsev, V.; Strasser, R.J. Temperature effects on pea plants probed by simultaneous measurements of the kinetics of prompt fluorescence, delayed fluorescence and modulated $820 \mathrm{~nm}$ reflection. PLoS ONE 2013, 8, e59433. [CrossRef]

19. Gao, J.; Li, P.; Ma, F.; Goltsev, V. Photosynthetic performance during leaf expansion in Malus micromalus probed by chlorophyll a fluorescence and modulated $820 \mathrm{~nm}$ reflection. J. Photochem. Photobiol. B Biol. 2014, 137, 144-150. [CrossRef]

20. Core, L.J.; Waterfall, J.J.; Lis, J.T. Nascent RNA sequencing reveals widespread pausing and divergent initiate at human promoters. Science 2008, 322, 1845-1848. [CrossRef]

21. Wu, Q.J.; Chen, Z.D.; Sun, W.J.; Deng, T.T.; Chen, M.J. De novo sequencing of the leaf transcriptome reveals complex lightresponsive regulatory networks in Camellia sinensis cv. Baijiguan. Front. Plant Sci. 2016, 7, 332. [CrossRef] [PubMed]

22. Wang, J.-Y.; Shen, J.-S.; Gu, M.; Cheng, T.-R.; Pan, H.-T.; Zhang, Q.-X. Leaf coloration and photosynthetic characteristics of hybrids between Forsythia 'Courtaneur' and Forsythia koreana 'Suwon Gold'. Hortscience 2017, 52, 1661-1667. [CrossRef]

23. Clark, S.M.; Vaitheeswaran, V.; Ambrose, S.J.; Purves, R.W.; Page, J.E. Transcriptome analysis of bitter acid biosynthesis and precursor pathways in hop (Humulus lupulus). BMC Plant Biol. 2013, 13, 12. [CrossRef] [PubMed]

24. Zhang, Z.; Wang, P.; Li, Y.; Ma, L.; Li, L.; Yang, R.; Ma, Y.; Wang, S.; Wang, Q. Global transcriptome analysis and identi- fication of the flowering regulatory genes expressed in leaves of Lagerstroemia indica. DNA Cell Biol. 2014, 33, 680-688. [CrossRef]

25. Lichtenthaler, H.K.; Wellburn, A.R. Determination of total carotenoids and chlorophylls a and b of leaf in different solvents. Biochem. Soc. Trans. 1983, 11, 591-592. [CrossRef]

26. Peng, J.G.; Jiang, X.R.; Jia, M.; Guo, L.; Gao, R.; Liu, Y. Contrasting patterns of sun-red and shade-green leaves of Buxus microphylla, in response to gradients of excess light during winter acclimation. Acta Physiol. Plant 2016, 38, 254. [CrossRef]

27. Strasser, R.J.; Tsimilli-Michael, M.; Srivastava, A. Analysis of fluorescence transient. In Chlorophyll Fluorescence: A Signature of Photosynthesis; Papageorgiou, G.C., Ed.; Advances in Photosynthesis and Respiration; Springer: Berlin/Heidelberg, Germany, 2004; pp. 321-362.

28. Han, Y.; Wan, H.; Cheng, T.; Wang, J.; Yang, W.; Pan, H.; Zhang, Q. Comparative RNA-seq analysis of transcriptome dynamics during petal development in Rosa chinensis. Sci. Rep. 2017, 7, 43382. [CrossRef]

29. Benjamini, Y.; Hochberg, Y. Controlling the false discovery rate: A practical and powerful approach to multiple testing. J. R. Stat. Soc. 1995, 57, 289-300. [CrossRef]

30. Shen, J.; Wu, Y.; Jiang, Z.; Xu, Y.; Zheng, T.; Wang, J.; Cheng, T.; Zhang, Q.; Pan, H. Selection and validation of appropriate reference genes for gene expression studies in Forsythia. Physiol. Mol. Biol. Plants 2020, 26, 173-188. [CrossRef]

31. Grabherr, M.G.; Haas, B.J.; Yassour, M.; Levin, J.Z.; Thompson, D.A.; Amit, I.; Adiconis, X.; Fan, L.; Raychowdhury, R.; Zeng, Q.D.; et al. Full-length transcriptome assembly from RNA-Seq data without a reference genome. Nat. Biotechnol. 2011, $29,644-652$. [CrossRef]

32. Li, B.; Dewey, C. RSEM: Accurate transcript quantification from RNA-Seq data with or without a reference genome. BMC Bioinform. 2011, 12, 323-326. [CrossRef] [PubMed]

33. Wang, S.; Wang, P.; Gao, L.; Yang, R.; Li, L.; Zhang, E.; Wang, Q.; Li, Y.; Yin, Z. Characterization and complementation of a chlorophyll-Less dominant mutant GL1 in Lagerstroemia indica. DNA Cell Biol. 2017, 36, 354-366. [CrossRef] [PubMed]

34. Li, Y.; Zhang, Z.; Wang, P.; Wang, S.; Ma, L.; Li, L.; Yang, R.; Ma, Y.; Wang, Q. Comprehensive transcriptome analysis discovers novel candidate genes related to leaf color in a Lagerstroemia indica yellow leaf mutant. Genes Genom. 2015, 37, 851-863. [CrossRef]

35. Li, B.Y. Study on the chlorophyll content in the leaves of Ligustrum vicaryi and L. quihoui. For. Sci. Tech. 2005, 30, 63-65.

36. Ma, Z.H.; Wang, H.T.; Wei, W.Q.; Yan, Y.H. Change of photosynthetic pigments and enzyme activities of hot pepper (Capsicum annuum) CMS line leaves with chartreuse marker. China Cucurbits Veg. 2011, 24, 20-24.

37. Zhou, Y.; Zhou, H.G.; Zhang, X.L. The Study on variegation and chimerism in ornamental plants. J. Guangxi Agric. Biol. 1999, 18, 68-73.

38. Oster, U.; Tanaka, R.; Tanaka, A.; Rüdigger, W. Cloning and functional expression of the gene encoding the key enzyme for chlorophyll $b$ biosynthesis (CAO) from Arabidopsis thaliana. Plant J. 2000, 21, 305-310. [CrossRef] 
39. Oukarroum, A.; Gharous, M.E.; Goltsev, V.; Strasser, R.J. Delayed fluorescence emission as a probe for the response of photosynthetic organisms to high temperature exposure: A comparative study. J. Lumin. 2016, 180, 321-327. [CrossRef]

40. Momchil, P.; Lyubka, K.; Andon, V.; Jaco, V.; Vasilij, G. Effects of different metals on photosynthesis: Cadmium and zinc affect chlorophyll fluorescence in durum wheat. Int. J. Mol. Sci. 2018, 19, 787. [CrossRef]

41. He, J.; Chee, C.W.; Goh, C.J. 'Photoinhibition' of Heliconia under natural tropical conditions: The importance of leaf orientation for light interception and leaf temperature. Plant Cell Environ. 1996, 19, 1238-1248. [CrossRef]

42. Pokorska, B.; Romanowska, E. Photoinhibition and D1 protein degradation in mesophyll and agranal bundle sheath thylakoids of maize. Funct. Plant Biol. 2007, 34, 844-852. [CrossRef] [PubMed]

43. Zhang, R.H.; Zhang, X.H.; Camberato, J.J.; Xue, J.Q. Photosynthetic performance of maize hybrids to drought stress. Russ. J. Plant Physiol. 2015, 62, 788-796. [CrossRef]

44. Liu, M. Response of photosynthesis and chlorophyll fluorescence to drought stress in two maize cultivars. Afr. J. Agric. Res. 2012, 7, 4751-4760. [CrossRef]

45. Mathur, S.; Allakhverdiev, S.I.; Jajoo, A. Analysis of high temperature stress on the dynamics of antenna size and reducing side heterogeneity of photosystem ii in wheat leaves (Triticum aestivum). Biochim. Biophys. Acta 2011, 1807, 22-29. [CrossRef]

46. Chen, S.G.; Yang, J.; Zhang, M.S.; Strasser, R.J.; Sheng, Q. Classification and characteristics of heat tolerance in ageratina adenophora populations using fast chlorophyll $a$ fluorescence rise o-j-i-p. Environ. Exp. Bot. 2016, 122, 126-140. [CrossRef]

47. Schansker, G.; Srivastava, A.; Govindjee, S.R.J. Characterization of the 820-nm transmission signal paralleling the chlorophyll $a$ fluorescence rise (OJIP) in pea leaves. Funct. Plant Biol. 2003, 30, 785-796. [CrossRef]

48. Schraser, S.M.; Wase, R.R.; Wacholtz, W.F.; Ort, D.R.; Sharkey, T.D. Thylakoid membrane responses to moderately high leaf temperature in Pima cotton. Plant Cell Environ. 2004, 27, 725-735. [CrossRef]

49. Zong, Y.Z.; Wang, W.F.; Xue, Q.W.; Shangguan, Z.P. Interactive effects of elevated co and drought on photosynthetic capacity and PSII performance in maize. Photosynthetica 2014, 52, 63-70. [CrossRef]

50. Noguchi, T. Dual role of triplet localization on the accessory chlorophyll in the photosystem II reaction center: Photoprotection and photodamage of the D1 protein. Plant Cell Physiol. 2002, 43, 1112-1116. [CrossRef]

51. Anderson, I.C.; Robertson, D.S. Role of carotenoids in protecting chlorophyll from photodestruction. Plant Cell 1960, 35, 531-534. [CrossRef]

52. Wang, C.; Liu, G.; Zhang, C.; He, F.; Li, Y.; Wu, J.; Shi, H. Changes in leaf photosynthetic characteristics and chloroplast ultrastructure during tobacco leaf growth and development. J. Jiangxi Agric. Univ. 2010, 32, 254-259. [CrossRef]

53. Heerden, P.V.; Strasser, R.J.; Kruger, G.H.J. Reduction of dark chilling stress in N-2-fixing soybean by nitrate as indicated by chlorophyll $a$ fluorescence kinetics. Physiol. Plant. 2010, 121, 239-249. [CrossRef] [PubMed]

54. Martínez-Júlvez, M.; Hurley, J.K.; Tollin, G.; Gómez-Moreno, C.; Fillat, M.F. Overexpression in E. coli, of the complete pet H gene product from anabaena: Purification and properties of a 49 kDA ferredoxin-NADP ${ }^{+}$reductase. Biochim. Biophys. Acta 1996, 1297, 200-206. [CrossRef] 